\title{
Characterization of St-Valerien-Like Virus Genome Detected in Japan
}

\author{
Go SATO $^{1)}$, Hisayuki IDO ${ }^{1)}$, Masahiro KIUCHI ${ }^{1)}$, Michiyo KATAOKA ${ }^{2)}$, Kazuhiko KATAYAMA ${ }^{3)}$ and \\ Yukinobu TOHYA ${ }^{1) *}$ \\ ${ }^{1)}$ Laboratory of Veterinary Microbiology, Department of Veterinary Medicine, College of Bioresource Sciences, Nihon University, 1866 \\ Kameino, Fujisawa, Kanagawa 252-0880, Japan \\ 2) Department of Pathology, National Institute of Infectious Diseases, Toyama 1-23-1 Shinjuku-ku, Tokyo 162-8640, Japan \\ ${ }^{3)}$ Department of Virology II, National Institute of Infectious Diseases, Gakuen 4-7-1, Musashi-murayama, Tokyo 208-2011, Japan
}

(Received 24 September 2013/Accepted 7 March 2014/Published online in J-STAGE 24 March 2014)

abstract. A novel calicivirus, St-Valerien-like virus (SVV), has been identified in asymptomatic swine in Canada, Italy and the U.S.A. In this study, we characterized a new SVV strain (NUP-24/JP) detected in fecal samples of swine in Japan. The NUP-24/JP genome had 6,409 nucleotides and 2 open reading frames (ORF1 and ORF2). ORF1 and ORF2 consist of 5,940 and 453 nucleotides, respectively. Phylogenetic analysis revealed that NUP-24/JP was closely related to other SVV strains, particularly to U.S.A. strain NC-WGS93C/US. This finding suggests that SVV is prevalent in swine worldwide. Using a baculovirus expression system, we successfully produced virus-like particles, which would be useful for seroepidemiological studies of SVV.

KEY WORDS: Caliciviridae, Japan, St-Valerien-like virus, swine, virus-like particle.

doi: 10.1292/jvms.13-0468; J. Vet. Med. Sci. 76(7): 1045-1050, 2014

The family Caliciviridae includes small non-enveloped viruses with single-stranded, positive-polarity RNA genomes of 7.4-8.3 kilobases [7]. The family consists of the Vesivirus (VESV), Lagovirus, Nebovirus, Norovirus (NoV) and Sapovirus ( $\mathrm{SaV}$ ) genera, as well as unassigned viruses $[6,12]$. Although caliciviruses are known to infect a broad range of animals, including humans, swine, cattle, rabbits and mice, each calicivirus is generally thought to have high specificity for its host species. In swine, viruses detected to date have been classified into 3 established genera in the family Caliciviridae; $\mathrm{SaV}$ [1, 9, 11, 13, 14, 16-19, 24, 28], NoV [15-17, 19, 21, 24, 28] and VESV [20]. Moreover, newly recognized caliciviruses, St-Valerien-like viruses (SVVs), were first identified in the feces of asymptomatic finisher swine in the province of Quebec, Canada, and were proposed as members of a potential genus of Caliciviridae [12]. SVV strains were also detected in swine in Italy and the U.S.A. $[5,22]$. These Italian and North American SVV strains showed a close genetic relationship. However, the prevalence and genetic diversity of SVV in countries other than Canada, Italy and the U.S.A. are unknown. In this study, we report the genome structure and phylogenetic properties of SVV detected in asymptomatic fattening swine in Japan. In addition, we describe here our attempts to produce baculovirus-expressed virus-like particles (VLPs) using the capsid protein-coding region of the Japanese SVV genome.

*Correspondence to: Tohya, Y., Laboratory of Veterinary Microbiology, Department of Veterinary Medicine, College of Bioresource Sciences, Nihon University, 1866 Kameino, Fujisawa, Kanagawa 252-0880, Japan. e-mail: tohya.yukinobu@nihon-u.ac.jp

(C2014 The Japanese Society of Veterinary Science

This is an open-access article distributed under the terms of the Creative Commons Attribution Non-Commercial No Derivatives (by-nc-nd) License $<$ http://creativecommons.org/licenses/by-nc-nd/3.0/>.
We collected a total of 76 fecal samples from 71 healthy and 5 sick swine at farms in Kanagawa and Tochigi prefectures. Swine were aged as follows; 16 nursing swine (1 to 3 weeks), 10 postweaning swine (4 to 10 weeks), 28 fattening swine (11 to 19 weeks), 17 finisher swine (20 to 24 weeks) and 5 unknown. All fresh fecal samples were placed in sterilized tubes and stored at $-80^{\circ} \mathrm{C}$ until use. Samples were prepared as $10 \%$ suspensions in sterilized phosphate-buffered saline. Prepared fecal suspensions were centrifuged at $20,000 \times g$ for $5 \mathrm{~min}$ at $4^{\circ} \mathrm{C}$, and supernatants were collected. Total RNAs were extracted from $140 \mu l$ of supernatants using the QIAamp Viral RNA Mini Kit (QIAGEN, Valencia, CA, U.S.A.). Yeast RNA (Applied Biosystems, Foster City, CA, U.S.A.) was used as a carrier. For screening, the specific primer set for calicivirus genome, P290 (sense; 5'-GATTACTCCAAGTGGGACTCCAC -3') and P289 (anti-sense; 5'-TGACAATGTAATCATCACCATA -3'), was used. The primers were broadly reactive, targeting highly conserved motifs of the RNA-dependent RNA polymerase coding region of the caliciviruses [10]. Reverse transcriptase polymerase chain reaction (RT-PCR) was performed using the PrimeScript ${ }^{\circledR}$ One Step RT-PCR Kit Ver.2 (Dye Plus) (TAKARA, Otsu, Japan) in accordance with the manufacturer's instructions. The expected size of the amplicon (311 bp) was analyzed by $2 \%$ agarose gel electrophoresis with SYBR safe DNA gel stain (Invitrogen, Carlsbad, CA, U.S.A.) and was visualized by UV. Amplicons were purified using the QIAquick Gel Extraction Kit (QIAGEN). Nucleotide sequences of amplicons were determined using an automated sequencer ABI3130 (Applied Biosystems) and the Big Dye Terminator Cycle Sequencing Kit ver. 3.1 (Applied Biosystems) and were assembled by ATGC computer software (Genetyx Corporation, Tokyo, Japan). To find homologous sequences, we performed a BLASTn search (http://blast. ncbi.nlm.nih.gov/Blast.cgi?PROGRAM=blastn\&BLAST_ 
Table 1. Primers used in this study

\begin{tabular}{|c|c|c|c|c|}
\hline Primer & Location & Sence & Sequence $\left(5^{\prime}-3^{\prime}\right)$ & Using \\
\hline P290 & $3674-3696$ & + & GATTACTCCAAGTGGGACTCCAC & $\begin{array}{l}\text { RT-PCR/ } \\
\text { 3'RACE PCR/ } \\
\text { Sequencing }\end{array}$ \\
\hline P289 & $3981-3962$ & - & TGACAATGTAATCATCACCATA & $\begin{array}{l}\text { RT-PCR/ } \\
\text { Sequencing }\end{array}$ \\
\hline 1st-Anchor25.TXR1 & & - & GCACATGACTACGGACTCAGGCGAT & 3'RACE PCR \\
\hline Anchor $30+\mathrm{T}$ & $3^{\prime}$ end & - & $\begin{array}{l}\text { GCACATGACTACGGACTCAGGCGAT- } \\
\text { ACATCAGCATGGAGCT (27) }\end{array}$ & 3'RACE PCR \\
\hline St-V-1F & $3867-3888$ & + & TACTGAACTGTGTGGCACACTG & Sequencing \\
\hline St-V-2F & $4480-4501$ & + & TCTTCCAGAGAACACGGCAGGC & Sequencing \\
\hline St-V-3F & $5009-5031$ & + & TTTGCCTTCACCATGGTGGTGCC & Sequencing \\
\hline St-V-4F & $5378-5397$ & + & GCAGAATACAACCCTGCCGA & Sequencing \\
\hline St-V-5F & $5869-5891$ & + & TTACTTCACCTTCCTGAGGTGGG & Sequencing \\
\hline St-V-7F & $442-461$ & + & CGTTCCACACCAACCTTGGG & Sequencing \\
\hline St-V-8F & $976-998$ & + & GATCTTGCATGACTCTTGTGCGG & Sequencing \\
\hline St-V-9F & $1557-1578$ & + & ACATCTATGTCCGTTCCCAGGC & Sequencing \\
\hline St-V-10F & $2107-2128$ & + & CCAAGACCTCTTGACCATCACC & Sequencing \\
\hline St-V-11F & $2618-2638$ & + & CGTAACCCAACACCACTTCTG & Sequencing \\
\hline St-V-12F & $3128-3148$ & + & CGTAACCCAACACCACTTCTG & Sequencing \\
\hline St-V-13F & $3736-3755$ & + & GACCAAACTGTCCACCTTCC & Sequencing \\
\hline St-V-14F & $166-186$ & + & CGGTGTGTACTTGTCACATGG & Sequencing \\
\hline St-V-15F & $1-22$ & + & GTGATTTGCAATGTCTGTTACG & Sequencing \\
\hline St-V-2R & $6009-5989$ & - & GCTGGCGACCTATTTTCTACC & Sequencing \\
\hline St-V-3R & $5528-5509$ & - & GGTGCAGGTGATGGCCTCAA & Sequencing \\
\hline St-V-4R & $5116-5097$ & - & ATCCCAGGTTCCCAGTTGGC & Sequencing \\
\hline St-V-5R & $4608-4587$ & - & GCCCAGATACCACAACCAACCA & Sequencing \\
\hline St-V-6R & $4129-4110$ & - & GGAGGACACGTTGGGAAGGA & Sequencing \\
\hline St-V-7R & $3556-3537$ & - & GGGTTTTCGGACCTGTGACA & Sequencing \\
\hline St-V-8R & $3060-3039$ & - & TTGCTGATGGCACACACCTCTG & Sequencing \\
\hline St-V-9R & $2489-2470$ & - & GGAGGAACCAGGCTTTCAGG & Sequencing \\
\hline St-V-10R & $1909-1888$ & - & ACAGCCCTTCAGACTCAACTCC & Sequencing \\
\hline St-V-11R & $1255-1236$ & - & TGGCAACTGCGATAGCACGC & Sequencing \\
\hline St-V-12R & $622-602$ & - & CTCTACCACTTACTTGCCACC & Sequencing \\
\hline St-V-13R & $258-239$ & - & GTCGTTCGCACCATCTCACA & Sequencing \\
\hline St-V-A1R & $504-485$ & - & GAGCAGGACTACGACTGCAA & 5'RACE PCR \\
\hline St-V-A2R & $482-461$ & - & GGAACTTCCCATTAGGATCC & 5'RACE PCR \\
\hline St-V-S1F & $508-527$ & + & CAACACACACACGATGCTTG & 5'RACE PCR \\
\hline St-V-S2F & $544-563$ & + & CCTGAGGTTTCTTTCCAAGG & 5'RACE PCR \\
\hline St-V-PR ${ }^{b)}$ & $569-582$ & - & (P) CTCAAAGTGCTCAC & 5'RACE PCR \\
\hline St-V-EcoR I Fc) & & + & $\begin{array}{l}\text { TATTGGAATTCGAAGCCATGGAGCT- } \\
\text { GGAGGGTGTGA }\end{array}$ & VLP \\
\hline St-V-Sal I R ${ }^{\mathrm{c}}$ & & - & $\begin{array}{l}\text { ATATCGTCGACT (30) AATGAGTTTTC- } \\
\text { AAAGCTCAGACCAATCTATAGTAC }\end{array}$ & VLP \\
\hline
\end{tabular}

a) Primers were published previously [9]. b) 5' end-phosphorylated RT primer. c) Underline indicates a restriction site.

PROGRAMS $=$ megaBlast $\&$ PAGE TYPE $=$ BlastSearch) $\quad$ of the Gene bank nucleotide database. The complete genome sequence of SVV in the sample was also determined with sequence-specific primers (Table 1). The $5^{\prime}$ and $3^{\prime}$ terminal sequences were amplified by $5^{\prime}$ and $3^{\prime}$ RACE methods using the 5'-Full RACE Core Set (TAKARA) and the PrimeScript ${ }^{\circledR}$ II High Fidelity RT-PCR Kit (TAKARA), respectively. In the 5' RACE method, 5' end phosphorylated primer, ST-V-PR, was used for the RT reaction. After degradation of RNA and circularization and/or formation of concatemers of the cDNA by T4 RNA ligase, the 5 ' terminal sequence (unknown region) in the cDNA became flanked with known sequence regions. The region including the $5^{\prime}$ terminal sequence was amplified by 1 st and 2nd PCR with external (St-V-S1F/ St-V-A1R) and internal (St-V-S2F/ St-V-A2R) primer sets, respectively (Table 1). In the 3' RACE method, the adaptor sequence was anchored at the $3^{\prime}$ terminal sequence using the Anchor30+T primer in the RT reaction. The $3^{\prime}$ terminal sequence was amplified by PCR with P290/ 1st-Anchor25.TXR1 primer set. The SVV nucleotide sequences were determined by direct sequencing as described above. Phylogenetic analyses were performed using the Neighbor-Joining (NJ) method with 


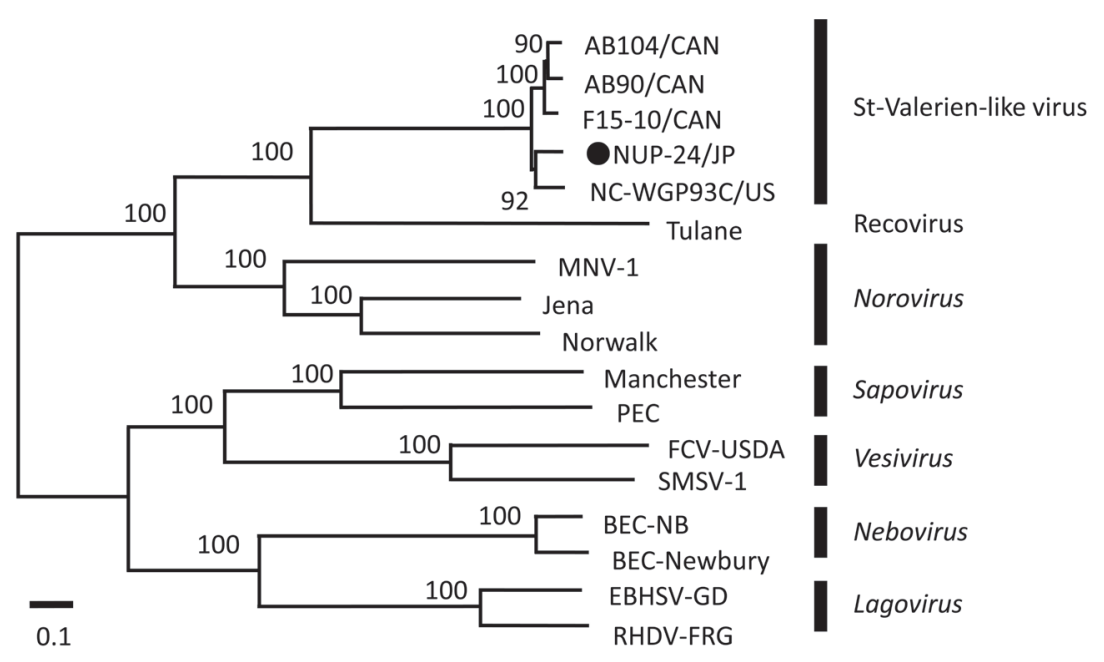

Fig. 1. Phylogenetic relationships of caliciviruses, including St-Valerien-like virus strains. The tree of complete genome sequences was constructed by the neighbor-joining method and was supported by 1,000 bootstrap replications. The NUP-24/JP strain identified in this study is indicated with a closed circle. The Genbank accession numbers of sequences are as follows: AB104/CAN, FJ355930; AB90/CAN, FJ355928; F15-10/CAN; FJ355929; NUP24/JP, AB863586; NC-WGP93C/US, GU592498; Tulane, EU391643; MNV-1, DQ285629; Jena, AJ011099; Norwalk, M87661; Manchester, X86560; PEC, AF182760; FCV-USDA, AY560118; SMSV-1, U15301; BEC-NB, AY082891; BEC-Newbury, DQ013304; EBHSVGD, Z69620; and RHDV-FRG, M67473.

MEGA ver. 5.05 (http://www.megasoftware.net/).

In this study, 2.6\% (2/76) sample sequences (NUP-24/ JP) detected from swine aged 4 months were identified as SVV positive. Because both swine were kept in the same pen and nucleotide sequences of the 2 samples showed complete accordance, we assumed that these sequences were derived from one strain (NUP-24/JP). The NUP-24/JP genome (Genbank accession No.: AB863586) had 6,409 nucleotides (exclude poly-A) and included two open reading frames (ORF1 and ORF2) with 5,940 and 453 nucleotides, respectively. Homologies of the ORF1 and ORF2 amino acid and nucleotide sequences (ORF1: 1,979 aa and 5,940 nt, ORF2: 150 aa and $453 \mathrm{nt}$ ) of the NUP-24/JP with other SVV strains [5, 12, 22] were as follows: full-sequence, $89.0-94.5 \%$; ORF1aa, 97.5-99.0\%; ORF1nt, 88.7-94.6\%; ORF2aa, 92.0-97.3\% and ORF2nt, 87.6-95.8\%. Amino acid motifs and putative cleavage sites of SVV [12] were also conserved (data not shown). The NJ-tree based on the complete nucleotide sequences of the NUP-24/JP and other caliciviruses indicated that the NUP-24/JP was included in the SVV cluster, particularly close to the NC-WGP93C/US strain [22] (Fig. 1). Results of phylogenetic analyses revealed that SVVs including NUP-24/JP showed high nucleotide homologies, although these strains were detected in the regions remote from one another (Canada, Italy, U.S.A. and Japan). This suggests that $\mathrm{SVV}$ is prevalent in swine in regions other than Europe and North America.

Other swine caliciviruses are known to show genetic diversity. Swine SaVs mainly comprise one genogroup (GIII), as well as multiple genogroups that have been proposed, but not yet classified (GVI, GVII, GVIII, GIX?, GX? and GXI?) $[19,25,26,28]$. Swine NoVs belong to one genogroup (GII), but are subdivided into three genotypes (GII/11, GII/18 and GII/19) $[23,26]$. The amino acid sequence homologies of their capsid regions are 31.6-99.8\% for SaVs [19] and 70.0$98.0 \%$ for NoVs [23]. A close relationship between SVVs $(\geq 95.5 \%$ ) showed in the phylogenetic tree (Fig. 1) raised the possibility that they have high genetic identity. There may be only 1 genotype within SVVs [22], although these homologies were based on nucleotide sequence data from small numbers of SVV. Further epidemiological studies of SVVs will thus be necessary.

We attempted to propagate the NUP-24/JP strain using three cell lines; swine kidney (LLC-PK1), porcine intestinal epithelial (PIE) and Vero cells. Infection studies using LLCPK1 cells were performed with bile acids, glycochenodeoxycholic acid and taurochenodeoxycholic acid, because it has been reported that bile acids in intestinal contents were essential for growth of swine $\mathrm{SaVs}$ in cultured cells $[2,3]$. Unfortunately, we found neither a cytopathic effect of SVV nor an increase in viral RNA in any cell line tested (data not shown). This suggests that SVV may have different infectivity against cultured cells when compared with swine $\mathrm{SaVs}$, although this could be attributed to low viral concentrations in the samples used in this study.

As propagation in cultured cells was unsuccessful, we next attempted to produce VLPs using the capsid proteincoding region of NUP-24/JP genome and the Bac-to-Bac ${ }^{\circledR}$ Baculovirus Expression System (Invitrogen), in accordance with a previously reported method [4]. Briefly, the 3 '-end 

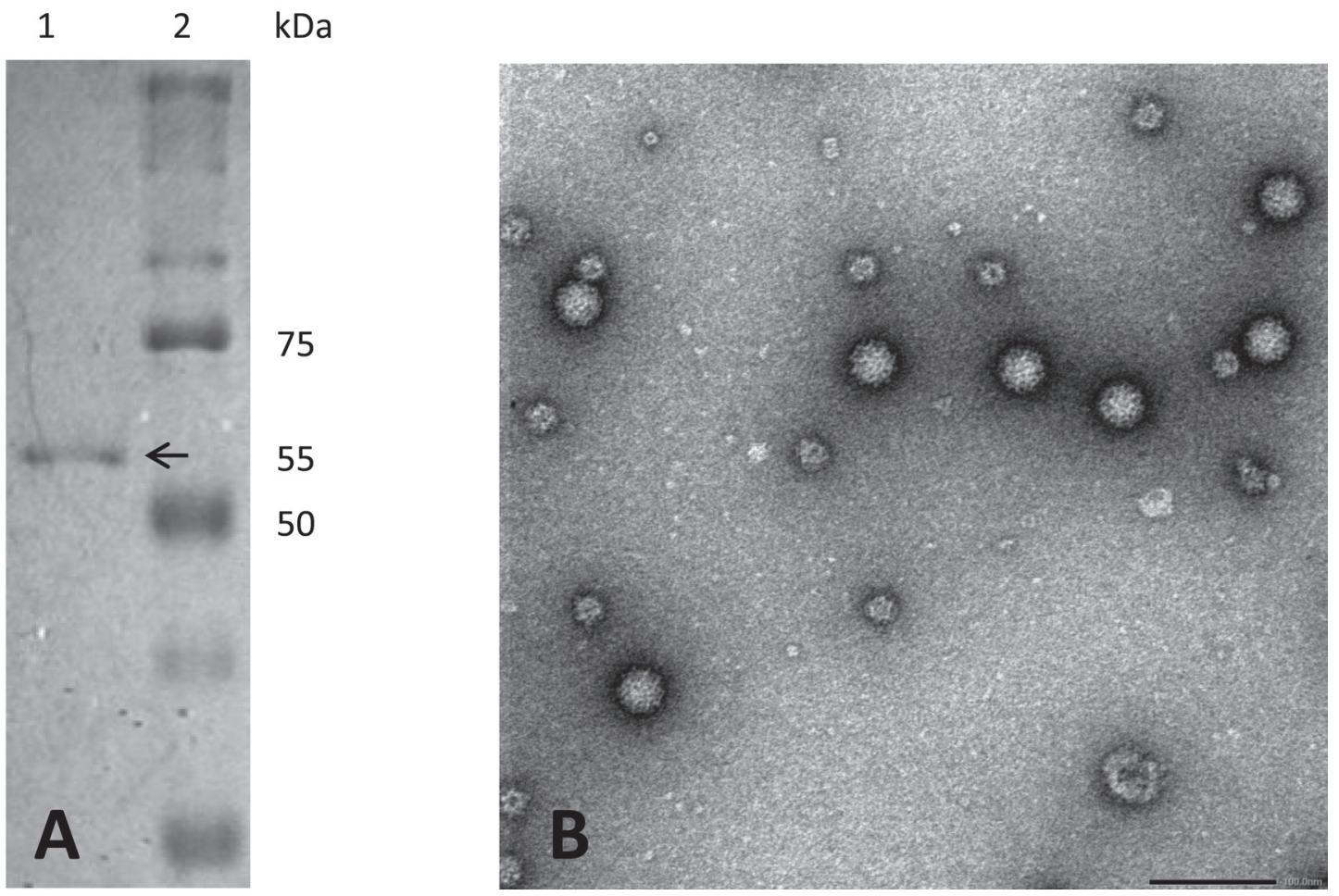

Fig. 2. Production of SVV VLPs using the Bac-to-Bac ${ }^{\circledR}$ Baculovirus Expression System. (A) SDS-PAGE of the recombinant capsid protein of the SVV, NUP-24/JP strain. Lane 1, capsid protein of NUP-24/JP VLPs concentrated from supernatants of Sf9 insect cells. ; Lane 2, Precision Plus Protein ${ }^{\mathrm{TM}}$ Standards (BIO-RAD). Arrow indicates SVV VP1 protein band. (B) EM analysis of the two types of VLP of SVV NUP-24/JP strain. The larger type has a diameter of approximately $45 \mathrm{~nm}$ with a characteristic cup structure on the surface. The smaller type has a diameter of approximately $30 \mathrm{~nm}$. Bar, $100 \mathrm{~nm}$.

region of the SVV genome (2,010 nt), including the VP1 and VP2 genes with $3^{\prime}$ UTR sequence, was amplified by RT-PCR with primers St-V-EcoRIF (5'-TATTGGAATTCGAAGCCATGGAGCTGGAGGGTGTGA-3'; EcoRI site underlined) and St-V-SalIR (5'-ATATCGTCGACT ${ }^{30}$ AATGAGTTTTCAAAGCTCAGACCAATCTATAGTAC-3'; SalI site underlined). The amplified DNA was ligated into the site between EcoRI and SalI of the pFastBacI ${ }^{\circledR}$ vector plasmid with the Rapid DNA Ligation Kit (Roche Diagnostics GmbH, Mannheim, Germany). The ligation product was cloned into DH5 $\alpha$ E. coli (TOYOBO, Osaka, Japan). Recombinant pFastBacI $^{\circledR}$ vector plasmids were harvested with the PureYield ${ }^{\mathrm{TM}}$ Plasmid Miniprep System Kit (Promega, Madison, WI, U.S.A.) and were transformed into the $\mathrm{DH} 10 \mathrm{Bac}^{\mathrm{TM}}$ E. coli (Invitrogen) for transposition of the VP1 gene into Bacmid DNA. Colonies containing recombinant Bacmid DNA were selected using X-Gal color screening, and the Bacmid DNA was harvested with the PowerPrep HP Bac Buffer Kit (Origene, Rockville, MD, U.S.A.). The recombinant capsid protein was produced in Spodoptera frugiperda (Sf9) insect cells by transfection of the recombinant Bacmid DNA with the Lipofectamine LTX PLUS ${ }^{\mathrm{TM}}$ Reagents (Invitrogen). Supernatant was harvested at 5 days post-inoculation as P1 recombinant baculovirus stock. The P1 stock was amplified by inoculation into Sf9 cells to generate high-titer viral stock. Amplification was performed twice, and each supernatant was harvested at 5 days postinoculation and was stored at $-80^{\circ} \mathrm{C}$ as $\mathrm{P} 2$ and $\mathrm{P} 3$ stock, respectively. Baculovirus particles and cell debris were removed from the $\mathrm{P} 3$ stock by centrifugation at $1,200 \times g$ for $5 \mathrm{~min}$ at $4^{\circ} \mathrm{C}$ and $20,000 \times g$ for $30 \mathrm{~min}$ at $4^{\circ} \mathrm{C}$ and by filtration with $\varphi 0.1-\mu \mathrm{m}$ filter. The P3 stock was further centrifuged at $150,000 \times g$ for $3 \mathrm{hr}$ at $4^{\circ} \mathrm{C}$ in a Beckman SW28.1 rotor to concentrate VLPs expected to be composed of the recombinant capsid protein. After centrifugation, the pellet containing VLPs was resuspended in Grace's Medium $\left(\mathrm{GIBCO}^{\circledR}\right.$, Carlsbad, CA, U.S.A.), and $5 \mathrm{ml}$ of $\mathrm{CsCl}$ solution $\left(1.27 \mathrm{~g} / \mathrm{cm}^{3}\right)$ containing the resuspended VLPs was prepared with Grace's Medium. The $\mathrm{CsCl}$ solution with the VLPs was centrifuged at $243,000 \times g$ for $18 \mathrm{hr}$ at $20^{\circ} \mathrm{C}$ in a Beckman SW50.1 rotor to obtain fraction including VLPs by density gradient centrifugation. VLPs in the fraction, discernible as a white band, were collected, diluted more than 10-fold with Grace's Medium and recovered by centrifugation at $150,000 \times g$ for $3 \mathrm{hr}$ at $4^{\circ} \mathrm{C}$. After removing the supernatant, purified VLPs were resuspended in Grace's Medium. Expression of capsid protein in the suspension was confirmed by SDS-PAGE and Coomassie brilliant blue (CBB) staining. VLPs were examined by electron microscopic observation.

SDS-PAGE and CBB staining showed a single band of 
approximately $55 \mathrm{kDa}$ (Fig. 2A), which corresponds to the molecular mass of VP1 of SVV [12]. Electron microscopic observation detected VLPs of two sizes (Fig. 2B). The larger type had a diameter of approximately $45 \mathrm{~nm}$ with a characteristic cup structure on the surface, and the smaller type had a diameter of approximately $30 \mathrm{~nm}$. The assembly of VLPs of two sizes (diameters of 38 and $23 \mathrm{~nm}$, respectively) has previously been reported in Norwalk virus (a prototype strain of human NoV) [27]. The authors suggested that VLPs of both sizes were composed of a $58 \mathrm{kDa}$ capsid protein and that the difference in VLP size depended on the number of units of capsid protein forming the VLPs. VLPs of 2 sizes (diameters $41-48$ and $26-31 \mathrm{~nm}$ ) have been also observed in $\mathrm{SaV}$ (NK24 strain) [8]. In our study on SVV, as only the $55 \mathrm{kDa}$ band was detected on SDS-PAGE, VLPs of 2 sizes also appear to be constructed from the intact capsid protein, VP1 of SVV. In addition, White et al. [27] indicated that the both VLPs have similar antigenic properties when analyzed with polyclonal and monoclonal antibodies. The VLPs of SVV, NUP24/JP successfully produced in this study should be useful as antigens for studying the seroprevalence rate of SVV infection in swine, such as age, species or farm-dependent differences in the prevalence of SVV-specific antibody.

In conclusion, we detected the SVV genome sequence of the NUP-24/JP strain in asymptomatic swine in Japan, thus suggesting that SVV is prevalent worldwide. Although we were unable to propagate NUP-24/JP using cell lines, we successfully produced VLPs, which would be useful for seroprevalence studies in the future.

ACKNOWLEDGMENTS. This study was supported in part by a Grant-in-Aid for Scientific Research (C) (No. 22580358) from the Japan Society for the Promotion of Science and grants from the Ministry of Education, Culture, Sports, Science and Technology and from the Ministry of Health, Labour and Welfare of Japan.

\section{REFERENCES}

1. Barry, A. F., Alfieri, A. F. and Alfieri, A. A. 2008. High genetic diversity in RdRp gene of Brazilian porcine sapovirus strains. Vet. Microbiol. 131: 185-191. [Medline] [CrossRef]

2. Chang, K.O., Sosnovtsev, S. S., Belliot, G., Wang, Q., Saif, L. J. and Green, K. Y. 2005. Reverse genetics system for porcine enteric calicivirus, a prototype sapovirus in the Caliciviridae. $J$. Virol. 79: 1409-1416. [Medline] [CrossRef]

3. Chang, K.O., Sosnovtsev, S. V., Belliot, G., Kim, Y., Saif, L. J. and Green, K. Y. 2004. Bile acids are essential for porcine enteric calicivirus replication in association with down-regulation of signal transducer and activator of transcription 1. Proc. Natl. Acad. Sci. U.S.A. 101: 8733-8738. [Medline] [CrossRef]

4. Di Martino, B., Di Profio, F., Ceci, C., Martella, V., Lavazza, A., Massirio, I. and Marsilio, F. 2012. Seroprevalence of StValerien-like caliciviruses in Italian swine. J. Gen. Virol. 93: 102-105. [Medline] [CrossRef]

5. Di Martino, B., Martella, V., Di Profio, F., Ceci, C. and Marsilio, F. 2011. Detection of St-Valerien-like viruses in swine, Italy. Vet. Microbiol. 149: 221-224. [Medline] [CrossRef]

6. Farkas, T., Sestak, K., Wei, C. and Jiang, X. 2008. Characterization of a rhesus monkey calicivirus representing a new genus of
Caliciviridae. J. Virol. 82: 5408-5416. [Medline] [CrossRef]

7. Green, K. Y., Ando, T., Balayan, M. S., Berke, T., Clarke, I. N., Estes, M. K., Matson, D. O., Nakata, S., Neill, J. D., Studdert, M. J. and Thiel, H. J. 2000. Taxonomy of the caliciviruses. J. Infect. Dis. 181 Suppl 2: S322-S330. [Medline] [CrossRef]

8. Hansman, G. S., Natori, K., Oka, T., Ogawa, S., Tanaka, K., Nagata, N., Ushijima, H., Takeda, N. and Katayama, K. 2005. Cross-reactivity among sapovirus recombinant capsid proteins. Arch. Virol. 150: 21-36. [Medline] [CrossRef]

9. Jeong, C., Park, S.I., Park, S.H., Kim, H.H., Park, S.J., Jeong, J.H., Choy, H. E., Saif, L. J., Kim, S.K., Kang, M.I., Hyun, B.H. and Cho, K.O. 2007. Genetic diversity of porcine sapoviruses. Vet. Microbiol. 122: 246-257. [Medline] [CrossRef]

10. Jiang, X., Huang, P. W., Zhong, W. M., Farkas, T., Cubitt, D. W. and Matson, D. O. 1999. Design and evaluation of a primer pair that detects both Norwalk- and Sapporo-like caliciviruses by RTPCR. J. Virol. Methods 83: 145-154. [Medline] [CrossRef]

11. Kim, H. J., Cho, H. S., Cho, K. O. and Park, N. Y. 2006. Detection and molecular characterization of porcine enteric calicivirus in Korea, genetically related to sapoviruses. J. Vet. Med. B Infect. Dis. Vet. Public Health 53: 155-159. [Medline] [CrossRef]

12. L'Homme, Y., Sansregret, R., Plante-Fortier, E., Lamontagne, A.M., Ouardani, M., Lacroix, G. and Simard, C. 2009. Genomic characterization of swine caliciviruses representing a new genus of Caliciviridae. Virus Genes 39: 66-75. [Medline] [CrossRef]

13. Martella, V., Bányai, K., Lorusso, E., Bellacicco, A. L., Decaro, N., Mari, V., Saif, L., Costantini, V., De Grazia, S., Pezzotti, G., Lavazza, A. and Buonavoglia, C. 2008. Genetic heterogeneity of porcine enteric caliciviruses identified from diarrhoeic piglets. Virus Genes 36: 365-373. [Medline] [CrossRef]

14. Martínez, M. A., Alcalá, A. C., Carruyo, G., Botero, L., Liprandi, F. and Ludert, J. E. 2006. Molecular detection of porcine enteric caliciviruses in Venezuelan farms. Vet. Microbiol. 116: 77-84. [Medline] [CrossRef]

15. Mattison, K., Shukla, A., Cook, A., Pollari, F., Friendship, R., Kelton, D., Bidawid, S. and Farber, J. M. 2007. Human noroviruses in swine and cattle. Emerg. Infect. Dis. 13: 1184-1188. [Medline] [CrossRef]

16. Mauroy, A., Scipioni, A., Mathijs, E., Miry, C., Ziant, D., Thys, C. and Thiry, E. 2008. Noroviruses and sapoviruses in pigs in Belgium. Arch. Virol. 153: 1927-1931. [Medline] [CrossRef]

17. Reuter, G., Bíró, H. and Szucs, G. 2007. Enteric caliciviruses in domestic pigs in Hungary. Arch. Virol. 152: 611-614. [Medline] [CrossRef]

18. Saif, L. J., Bohl, E. H., Theil, K. W., Cross, R. F. and House, J. A. 1980. Rotavirus-like, calicivirus-like, and 23-nm virus-like particles associated with diarrhea in young pigs. J. Clin. Microbiol. 12: 105-111. [Medline]

19. Scheuer, K. A., Oka, T., Hoet, A. E., Gebreyes, W. A., Molla, B. Z., Saif, L. J. and Wang, Q. 2013. Prevalence of porcine noroviruses and molecular characterization of emerging porcine sapoviruses from finisher swine in the United States, and unified classification scheme for sapoviruses. J. Clin. Microbiol. 51: 2344-2353. [Medline] [CrossRef]

20. Smith, A. W., Skilling, D. E., Cherry, N., Mead, J. H. and Matson, D. O. 1998. Calicivirus emergence from ocean reservoirs: zoonotic and interspecies movements. Emerg. Infect. Dis. 4: 13-20. [Medline] [CrossRef]

21. Sugieda, M., Nagaoka, H., Kakishima, Y., Ohshita, T., Nakamura, S. and Nakajima, S. 1998. Detection of Norwalk-like virus genes in the caecum contents of pigs. Arch. Virol. 143: 1215-1221. [Medline] [CrossRef]

22. Wang, Q., Scheuer, K., Zhang, Z., Gebreyes, W. A., Molla, B. Z., 
Hoet, A. E. and Saif, L. J. 2011. Characterization and prevalence of a new porcine calicivirus in swine, United States. Emerg. Infect. Dis. 17: 1103-1106. [Medline] [CrossRef]

23. Wang, Q.H., Han, M. G., Cheetham, S., Souza, M., Funk, J. A. and Saif, L. J. 2005. Porcine noroviruses related to human noroviruses. Emerg. Infect. Dis. 11: 1874-1881. [Medline] [CrossRef]

24. Wang, Q.H., Souza, M., Funk, J. A., Zhang, W. and Saif, L. J. 2006. Prevalence of noroviruses and sapoviruses in swine of various ages determined by reverse transcription-PCR and microwell hybridization assays. J. Clin. Microbiol. 44: 2057-2062. [Medline] [CrossRef]

25. Wang, Q.H., Han, M. G., Funk, J. A., Bowman, G., Janies, D. A. and Saif, L. J. 2005. Genetic diversity and recombination of por- cine sapoviruses. J. Clin. Microbiol. 43: 5963-5972. [Medline] [CrossRef]

26. Wang, Q.H., Costantini, V. and Saif, L. J. 2007. Porcine enteric caliciviruses: genetic and antigenic relatedness to human caliciviruses, diagnosis and epidemiology. Vaccine 25: 5453-5466. [Medline] [CrossRef]

27. White, L. J., Hardy, M. E. and Estes, M. K. 1997. Biochemical characterization of a smaller form of recombinant Norwalk virus capsids assembled in insect cells. J. Virol. 71: 8066-8072. [Medline]

28. Yin, Y., Tohya, Y., Ogawa, Y., Numazawa, D., Kato, K. and Akashi, H. 2006. Genetic analysis of calicivirus genomes detected in intestinal contents of piglets in Japan. Arch. Virol. 151: 1749-1759. [Medline] [CrossRef] 